\title{
Regularities of changes in material properties for some polymer-concrete ratios
}

\author{
Aleksandr Ilyin ${ }^{1,}$, Mikhail Permyakov ${ }^{1}$, Vladimir Andreyev ${ }^{1}$, and Tamara Krasnova ${ }^{1, *}$ \\ ${ }^{1}$ Nosov Magnitogorsk State Technical University, prospekt Lenina, the house 38, Magnitogorsk, \\ 455000, Russia
}

\begin{abstract}
Nuclear power has important fundamental features that are absent in other power generation technologies, since nuclear fuel has million times larger energy content, while nuclear waste is relatively low in volume, which makes it reliably localizable. This paper presents a study of the strength and electrical insulation properties of polymer concretes in a wide range of altering the polymer-concrete ratios. The analysis has identified an optimal polymer-cement composition for electrical insulation. It is herein demonstrated that polymer cements can be used for insulation of electromagnets. The tasks of creating new materials that meet the requirements of the time, the development of technologies that go beyond the solution of standard practical problems of the construction industry, and, accordingly, the emergence of related problems are the picture of modernity. This paper is useful for further developments in the construction industry, designed to solve the problems of using modern technologies and materials that have a negative impact on the environment. Thus, this allows the application of this approach in complex construction situations, including when working in environmentally complex areas, for leveling radiation.
\end{abstract}

\section{Introduction}

Research and innovation in the third-millennium construction industry is characterized by the rapid development of technology, devices, and new materials [1]. Technological progress gives rise to problems associated with the need to protect the environment and ecology in general from the technogenic effects of industrial production [2]. Technological progress has given rise to the problem of creating a radiation-resistant electrical insulation capable of withstanding radiation loads above $5 \times 10^{7}$ Gy (the absorbed-dose limit for electrical insulation made of epoxy resin reinforced with glass tape [3]). Loss of the mechanical strength of the polymer is the main factor behind the failures of electromagnets with such insulation when exposed to radiation.

This is why mineral electrical insulation is used in devices intended to withstand high radiation. The most popular type is electrical insulation made of rectangular-section coaxial cables, where magnesia and asbestos-cement electrical insulation is used as the insulator

* Corresponding author: toma.krasnova.70@mail.ru 
[4]. The main disadvantage of using electrical insulation with magnesia is the extremely low electromagnet-winding fill factor ( $40 \%$ at best), causing the winding cost to skyrocket. Asbestos-cement electrical insulation brings the fill factor close to the values typical of ordinary windings with epoxy insulation. However, the porosity and water absorption of cements necessitates enclosing the electromagnet windings in a sealed wrapper to stabilize the insulating quality of the material. The technology of making asbestos-cement windings is rather complex and requires special equipment, making it only advisable to use where the dose absorbed during the service life can reach $10^{10} \ldots 10^{11} \mathrm{~Gy}$, i.e. two or three orders of magnitude higher than the limit doses for polymer insulation [5]. Some electromagnets have to sustain radiation below $10^{\mathbf{1 0}} \ldots 10^{\mathbf{1 1}} \mathrm{Gy}$, still exceeding the epoxy-insulation limits by far. For insulating the windings of such electromagnets, it is highly desirable to simplify the winding-making technology while also attaining a radiation resistance above that of epoxy insulation.

To that end, one could use polymer concretes, as found out by analyzing the properties of various materials whose radiation resistance is between that of asbestos-cement electrical insulation and its epoxy counterpart.

A polymer concrete is a material based on a composite binder, which contains an organic polymer and a non-organic binder.

The goal of this research was to make the polymer component generate its own independent structural element in the hardened material while the concrete component generates its own structural element in the same material.

Based on this concept, we formulated the main idea of using polymer concretes, i.e. to distribute the functions of electrical insulation between the polymer-concrete components. The mineral component would provide mechanical longevity and radiation resistance, while the polymer component would considerably improve the electrophysical properties of electrical insulation; as known, the dielectric properties of polymers degrade at a much lower rate than their mechanical properties for the same radiation dose.

As polymer concretes have not been used for electrical insulation so far, the paper presents the results of studying the mechanical and dielectric properties of polymer concretes.

Depending on the polymer component type, polymer concretes can be fluid, making them technologically similar to cast cement mixtures, or they can be adhesive and viscous like ordinary epoxy resins. As we meant to use a polymer-like technology, we focused on adhesive polymer concretes; such concretes are mechanically better than their fluid counterparts [6].

\section{Methods and Materials}

We used the factor variation method to study the correlation of mechanical, electrical, and technological properties of polymer concretes of different composition. The following factors were assumed to be the determinants of these properties:

- polymer-concrete ratio $(\mathrm{P} / \mathrm{C})$, which caried from $0 \div 1$ to $1 \div 0$ by mass;

- polymer-system type and filler type.

The following materials were used to make a polymer-concrete mixture: high-aluminate cement; ED -8, ED -16, ED -22, ED-49, UP -610, and DEG -1 epoxy resins; m-FDA, pABA, UP -606/2, and TETA hardeners; water; emulsifier (to combine the polymer system with the mortar); quartz sand; glass tape.

The mixture was cured as follows:

1. first cured at normal temperature for two to three hours.

2. then exposed to heat and moisture treatment in saturated vapor at $(90 \pm 2)^{\circ} \mathrm{C}$ for 15 hours so that the cement would harden and the epoxy resin begin to harden. 
3. then dried at $150^{\circ} \mathrm{C}$ for four to seven hours so that the epoxy resin would be cured completely, and the residual moisture removed.

In order to study the electro-insulating properties of this polymer-concrete, we adopted standards applicable to solid electrical insulators, whereas the strength was compared against polymer standards.

Radiative destruction of the polymer structure was simulated by either thermal aging or polymer non-curing.

\section{Results}

Polymer-concrete materials had previously been studied in a limited range of polymerconcrete $(\mathrm{P} / \mathrm{C})$ ratios from 0.01 to $0.5[6]$. This is why it was of practical interest to trace the changes in polymer-concrete properties over the entire $\mathrm{P} / \mathrm{C}$ ratio range, from pure concrete to pure polymer.

Figure 1 presents the results for compositions specified in the table (adhesive polymer concretes).

Table 1. Compositions

\begin{tabular}{|l|l|l|l|l|l|l|l|l|}
\hline \multirow{2}{*}{ Materials } & \multicolumn{9}{|l|}{ Components by wt.\% } \\
\cline { 2 - 10 } & 1 & 2 & 3 & 4 & 5 & 6 & 7 & 8 \\
\hline Cement & 52.60 & 49.60 & 47.00 & 44.70 & 33.30 & 19.20 & 8.40 & 0 \\
\hline Sand & 26.30 & 24.80 & 3.5 & 22.30 & 16.60 & 9.60 & 4.20 & 0 \\
\hline Water & 21.10 & 19.90 & 18.90 & 18.00 & 13.30 & 7.70 & 3.5 & 0 \\
\hline Emulsifier & 0 & 0.31 & 0.26 & 0.24 & 0.17 & 0.14 & 0.08 & 0 \\
\hline ED -20 resin & 0 & 4.90 & 9.40 & 13.42 & 33.30 & 57.60 & 76.21 & 90.91 \\
\hline $\begin{array}{l}\text { UP -606/2 } \\
\text { hardener }\end{array}$ & 0 & 0.49 & 0.94 & 1.34 & 3.33 & 5.76 & 7.62 & 9.09 \\
\hline
\end{tabular}

We controlled the following properties of the materials: electrical resistance after 450-day exposure at $20^{\circ} \mathrm{C} \pm 2{ }^{\circ} \mathrm{C}$ and a relative humidity of $60 \% \pm 5 \%$; electrical resistance and compressive strength after one-hour thermal aging at $280^{\circ} \mathrm{C}$; compressive strength after 100-hour exposure to concentrated hydrochloric acid; compressive strength and tensile strength after technological processing; water absorption by weight.

Studies showed that such correlations were generic for all types of polymer concretes. When analyzing the data, we noted a considerable difference in the properties of pure concrete (Composition 1) and epoxy polymer (Composition 8): thus, the electrical resistance /Figure 1, Curve $1 /$ at $60 \% \pm 5 \%$ rose by almost 6 orders of magnitude when increasing the amount of the polymer binder, with the greatest increase $(3.5 \div 4$ orders $)$ being observed at $\mathrm{P} / \mathrm{C}$ of up to 0.3 . Within this $\mathrm{P} / \mathrm{C}$ range, we also observed a considerable reduction ( 5 times /Curve $3 /$ ) in water absorption. Thermal aging caused the polymer part to degrade severely, as indicated by the low strength of Composition $8 /$ Curve $6 /$. At $\mathrm{P} / \mathrm{C}=0.1$ $\div 0.3$, materials withstood temperature much better. 


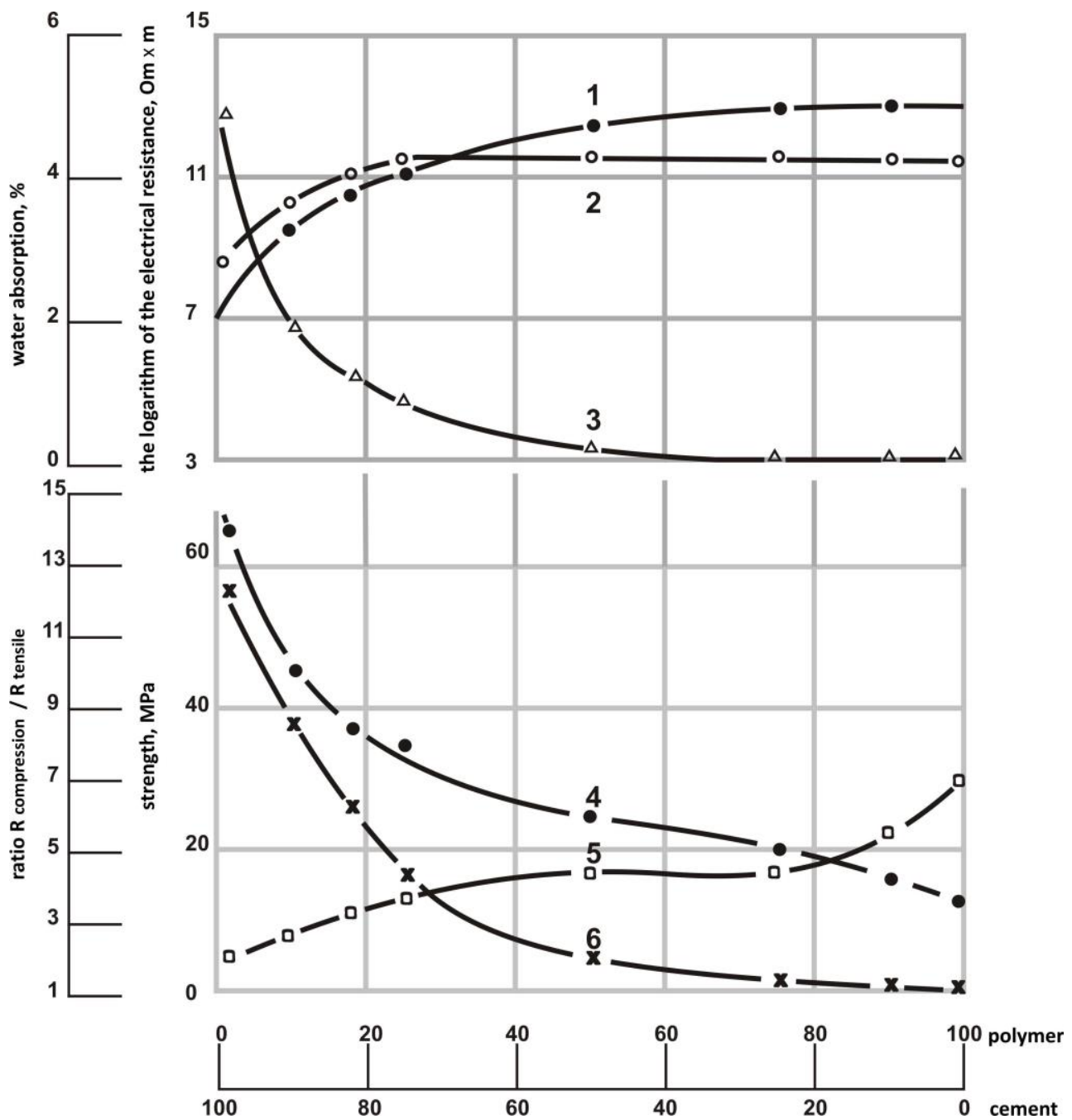

Fig. 1. Changes in properties pertaining to different polymeric binder / concrete binder ratios: $1-$ electrical resistance at a humidity of $60 \% \pm 5 \% ; 2$ - electrical resistance after thermal aging at $280^{\circ} \mathrm{C}$; 3 - water absorption; 4 - compressive-strength to tensile-strength ratio; 5 - tensile strength; 6 compressive strength after aging at $280^{\circ} \mathrm{C}$.

Figure 2 shows changes in the strength and electrical resistance resistance of polymerconcrete materials. Figure 2 presents the results of studying the strength of polymer concrete /Curve 1/, polymer structure /Curve 2/, and mineral structure /Curve 3/. Apparently, the most promising polymer concretes are those with a $\mathrm{P} / \mathrm{C}$ of up to 0.2 , but no more. In this region, the electrical resistance of the material increases by almost three orders of magnitude compared to pure concrete, while the mineral-structure strength is reduced by $30 \div 35 \%$. Therefore, even after the polymer loses its strength, the material will remain physically integral and sufficiently resistant.

These data suggest that in terms of radiation resistance, these $\mathrm{P} / \mathrm{C}$ ratios will be inbetween concretes and epoxies. The most considerable improvement in radiation resistance is expected from such $\mathrm{P} / \mathrm{C}$ ratios, where the mineral structure is at the strongest [7]. 

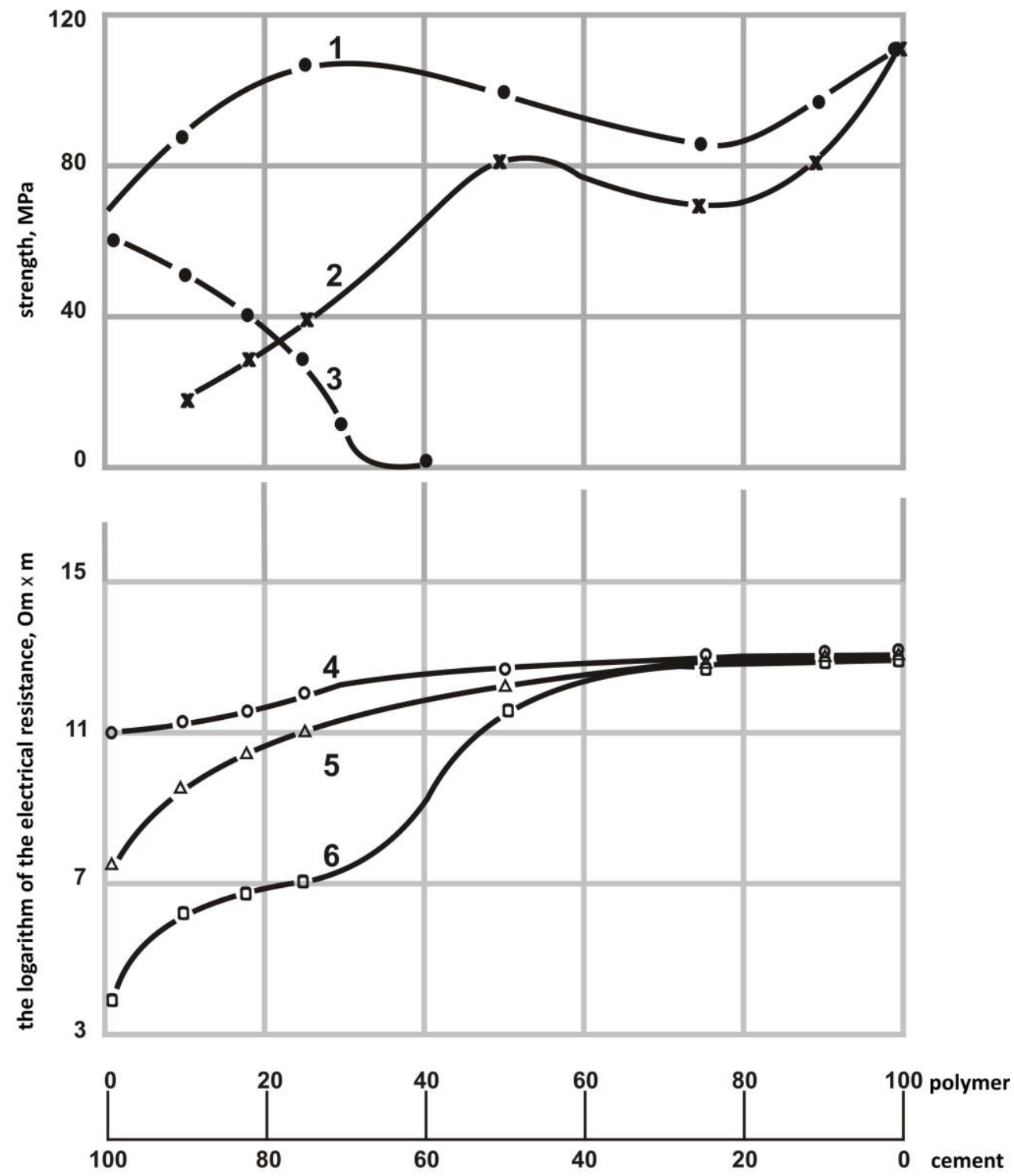

Fig. 2. Changes in properties pertaining to different polymeric binder / concrete binder ratios:

Compressive strength: 1 - polymer concrete; 2 - polymer structure; 3 - concrete structure. Electrical resistance: 4 - at a humidity of $0 \% \div 5 \% ; 5$ - at $55 \% \div 65 \% ; 6$ - at $95 \% \div 100 \%$.

The dielectric properties of polymer concretes greatly depend on the environmental humidity as well as on the material $\mathrm{P} / \mathrm{C}$ ratio, see Figure 2 . When exposed to air at a relative humidity of $95 \% \div 100 \%$, the electrical resistance of concretes is reduced by seven orders of magnitude /Curves 4 and 6/, whereas that of polymeric ones $(\mathrm{P} / \mathrm{C}>0.5)$ is only reduced by 0.5 against a dried material. At a normal humidity of $55 \% \div 65 \%$, the electrical resistance of concretes drops by four orders of magnitude, which is why windings with insulation made of such materials have to be sealed.

For polymer concretes with a $\mathrm{P} / \mathrm{C}=0.2$ or more, the reduction in resistance is confined to only one order of magnitude, meaning that polymer-concrete insulated windings do not require sealing. 
To shut the books, Table 2 presents the main properties of the optimized polymerconcrete composition $(\mathrm{P} / \mathrm{C}=0.15, \mathrm{ED}-22 \mathrm{resin}$, and $\mathrm{p}$ - ABA hardener) at a humidity of $55 \% \div 65 \%[8]$.

Table 2. Main properties of the optimized polymer-concrete composition

\begin{tabular}{|l|l|}
\hline indicator & value \\
\hline compressive strength after steaming, $\mathrm{MPa}$ & 50 \\
\hline compressive strength after steaming and drying, $\mathrm{MPa}$ & 80 \\
\hline tensile strength, $\mathrm{MPa}$ & 7.5 \\
\hline bending strength, MPa & 19.0 \\
\hline copper shear adhesion, MPa & 4.5 \\
\hline electrical resistance, Ohm $\times \mathrm{m}$ & $10^{9}$ \\
\hline breakdown voltage, $\mathrm{MV} / \mathrm{m}$ & 3.5 \\
\hline dielectric permittivity at $50 \mathrm{kHz}$ & 7.7 \\
\hline loss tangent at $50 \mathrm{kHz}$ & 0.09 \\
\hline shrinkage, \% & 0.18 \\
\hline coefficient of linear expansion, deg $^{-1}$ & $15 \times 10^{-6}$ \\
\hline
\end{tabular}

The unique properties of this material mean it can be used not only for electrical insulation, but also for erecting the load-bearing structures of facility foundations, e.g. pile foundations [9-10]. Use of the electrical-insulation material we have developed will extent the service life of buildings and structures; as of today, there have been developed methods for precise calculation of their residual safe-to-operate life [11-14]. The use of polymer cement can solve the problems of environmental production in the construction industry as a whole. This approach will allow the use of polymer cement in various construction technologies, such as: the method of "wall in the ground" and special methods of concreting, such as concrete shotcrete [15].

\section{Conclusion}

The paper demonstrates the possibility of using polymer concretes for electrical insulation of radiation-loaded elements of nuclear plants. The use of polymer cement in this way expands the possibilities of construction technologies. A valuable feature is the ability to adapt existing construction technologies to solve environmental problems.

\section{References}

1. K. M. Voronin et al., Scientific Research and Innovations in Construction and Engineering Communications in the Third Millennium, et al. The Bulletin of the Nosov Magnitogorsk State Technical University, 2, pp. 49-50, (2009)

2. M. B Permyakov, Relevant Problems of Construction Industry, (Magnitogorsk, 2013)

3. D. S. Phillips et al., The selection and properties of epoxide resins used for the insulation of magnet systems in radiation environment. CERN 81-05, Geneva, (1981)

4. R. L. Keizer, M. Mottier, Radiation resistant magnets CERN 82-05, (Geneva, 1982) 
5. M. Permyakov, A. Ilyin, V. Andreev, K. Voronin, T. Krasnova, MATEC Web of Conferences, 251, 02007 (2018)

6. Yu. S. Cherkinsky, Polymer Concrete, 2nd ed., revised and updated. (Moscow, Stroyizdat, 1984)

7. A. A. Bolberov, V. Zarucheysky, A. N. Ilyin, K. N. Popov, V. N. Solovyov, O. L. Figovsky, Sealant for Insulation of Electrotechnical Machines, Inventor's Certificate No. 1254730

8. A. Ilin, E. Chernyshova, M. Permyakov, V. Andreev, A. Krishan, R. Sabirov, Journal of Engineering and Applied Sciences. 11(1), 13-16, (2016)

9. M. B. Permyakov, A. V. Vesyolov, A. M. Permyakova, Concrete Technologies. Issue 6(95), pp. 30-32, (2014)

10. A. V. Veselov, M. B. Permyakov, I. S. Trubkin, A. Tokarev, Precast-monolithic composite pile and its manufacturing technology, [Housing construction], 11, pp. 1517 (2012)

11. M. B. Permyakov, Advances in Environmental Biology, 8, Iss. 7. 1983-1986, (2014)

12. M. B. Permjakov, Advances in Environmental Biology, 8, Iss. 7. pp. 1969-1973, (2014)

13. M. B. Permyakov, Architecture. Construction. Education, 2, 66-72 (2014)

14. M. B. Permyakov, Architecture. Construction. Education, 1, 169-176 (2012)

15. M. B. Permyakov, S. V. Timofeev, Architecture. Construction. Education, 2, 129-138 (2013) 